\title{
Endoscopic Management of Bile Leakage after Liver Transplantation
}

\author{
Dongwook Oh, Sung Koo Lee, Tae Jun Song, Do Hyun Park, Sang Soo Lee, Dong-Wan Seo, and Myung-Hwan Kim \\ Division of Gastroenterology, Department of Internal Medicine, Asan Medical Center, University of Ulsan College of Medicine, Seoul, Korea
}

Background/Aims: Endoscopic retrograde cholangiopancreatography (ERCP) can be an effective treatment for bile leakage after liver transplantation. We evaluated the efficacy of endoscopic treatment in liver transplantation in patients who developed bile leaks. Methods: Forty-two patients who developed bile leaks after liver transplantation were included in the study. If a bile leak was observed on ERCP, a sphincterotomy was performed, and a nasobiliary catheter was then inserted. If a bile leak was accompanied by a bile duct stricture, either the stricture was dilated with balloons, followed by nasobiliary catheter insertion across the bile duct stricture, or endoscopic retrograde biliary drainage was performed. Results: In the bile leakage alone group (22 patients), endoscopic treatment was technically successful in 19 (86.4\%) and clinically successful in 17 (77.3\%) cases. Among the 20 patients with bile leaks with bile duct strictures, endoscopic treatment was technically successful in 13 (65.0\%) and clinically successful in 10 (50.0\%) cases. Among the 42 patients who underwent ERCP, technical success was achieved in 32 (76.2\%) cases and clinical success was achieved in 27 (64.3\%) cases. Conclusions: ERCP is an effective and safe therapeutic modality for bile leaks after liver transplantation. ERCP should be considered as an initial therapeutic modality in post-liver transplantation patients. (Gut Liver 2015;9:417-423)

Key Words: Cholangiopancreatography, endoscopic retrograde; Bile leakage; Liver transplantation

\section{INTRODUCTION}

Although cadaveric donor liver transplantation (CDLT) is widely used to treat end-stage liver disease, cadaveric donors are limited in East Asian countries such as Korea and Japan. Thus, living donor liver transplantation (LDLT) has been used mainly in Asia, particularly in Korea and Japan. ${ }^{1}$ However,
LDLT has potential risks associated with the small graft size for the recipient and the small remnant liver for the donor. ${ }^{2,3}$ To solve these problems, LDLT with dual grafts from two donors is performed, particularly in Korea.

Biliary adverse events are the main complications after liver transplantation $^{4}$ and are an important cause of postoperative morbidity and mortality. ${ }^{5,6}$ The rate in transplant recipients ranges from $6 \%$ to $29 \% .^{7}$ Biliary adverse events after transplantation include anastomotic stricture, bile leakage, stones or debris, and Oddi dysfunction. ${ }^{4,8}$ Anastomotic stricture and bile leakage are the most common, ${ }^{9}$ with bile leakage the most frequent cause of biliary tract-related death after liver transplantation. ${ }^{7}$ Early detection and appropriate management are critical for minimizing secondary adverse events associated with bile leakage. ${ }^{10,11}$ Surgery or percutaneous transhepatic biliary drainage (PTBD) has been used to treat bile leaks after liver transplantation. ${ }^{9,12}$ However, surgical repair has a higher rate of adverse events and death, and PTBD has a lower rate of success because of biliary dilation. ${ }^{12}$ Endoscopic retrograde cholangiopancreatography (ERCP), the gold standard diagnostic pathway for biliary disease, is the preferred method of evaluation. ${ }^{4,6}$ ERCP is a safe and effective treatment for bile leakage. ${ }^{7}$ Several studies have reported the use of ERCP for the endoscopic treatment of bile leakage, with a success rate of approximately 70\% to $80 \% .^{4,7-9,12-14}$

The aim of this study was to evaluate the efficacy of endoscopic treatment in patients who undergo CDLT, LDLT or LDLT with dual grafts and develop bile leaks or bile leaks combined with bile duct strictures.

\section{MATERIALS AND METHODS}

\section{Patients}

Between January 2003 and December 2008, a total of 1,430 adult patients (age, 18 to 65 years) underwent adult-to-adult liver transplantation at our center. Of these patients, 1,095 un-

Correspondence to: Sung Koo Lee

Division of Gastroenterology, Department of Internal Medicine, Asan Medical Center, 88 Olympic-ro 43-gil, Songpa-gu, Seoul 138-736, Korea

Tel: +82-2-3010-3186, Fax: +82-2-476-0824, E-mail: sklee@amc.seoul.kr

Received on March 27, 2014. Revised on July 30, 2014. Accepted on September 18, 2014. Published online on February 26, 2015 pISSN 1976-2283 eISSN 2005-1212 http://dx.doi.org/10.5009/gnl14117

@ This is an Open Access article distributed under the terms of the Creative Commons Attribution Non-Commercial License (http://creativecommons.org/licenses/by-nc/3.0) which permits unrestricted non-commercial use, distribution, and reproduction in any medium, provided the original work is properly cited. 
derwent LDLT, 195 underwent LDLT with dual grafts, and 140 underwent CDLT. In CDLT and LDLT, biliary reconstruction was by duct-to-duct biliary reconstruction or Roux-en-Y hepaticojejunostomy as determined by the underlying liver disease, relative donor sizes, recipient bile ducts, and prior biliary surgery. When there was a size discrepancy in the caliber between the donor and recipient duct, or the bile duct was short, a Rouxen-Y hepaticojejunostomy was performed. In CDLT, bile duct reconstruction was established with duct-to-duct anastomosis $(\mathrm{n}=130)$ with a T-tube $(\mathrm{n}=124)$ or an internal stent $(\mathrm{n}=4)$ or without a stent $(n=2)$. Ten patients underwent CDLT with Rouxen-Y hepaticojejunostomy with a T-tube $(n=8)$ or without a stent $(\mathrm{n}=2)$. In LDLT, bile duct reconstruction was established with duct-to-duct anastomosis ( $\mathrm{n}=952)$ with an external stent $(n=679)$ or an internal stent $(n=188)$ or without a stent $(n=85)$. In 97 patients who underwent LDLT, the bile ducts were reconstructed with Roux-en-Y hepaticojejunostomy with an external stent $(n=68)$ or an internal stent $(n=18)$ or without a stent $(n=11)$. In 46 patients who underwent LDLT, the bile ducts were reconstructed with duct-to-duct anastomosis with Roux-en-Y hepaticojejunostomy with an external stent $(n=30)$ or an internal stent $(n=10)$ or without a stent $(n=6)$. In LDLT with dual grafts, the bile ducts were reconstructed with duct-to-duct anastomosis with Roux-en-Y hepaticojejunostomy ( $\mathrm{n}=195)$ with an external and an internal stent $(\mathrm{n}=185)$. Ten patients underwent LDLT with dual grafts without stents.

Of the patients who underwent liver transplantation, bile leakage occurred in 42 (2.9\%) patients. These patients were included in this study.

\section{Definition and diagnosis of bile leaks and bile duct stric- tures}

The diagnosis of bile leakage was based on clinical symptoms (fever, abdominal pain, and increased abdominal girth), laboratory tests, biloma on computed tomography, and leakage on diisopropyl iminodiacetic acid scanning. Bile leakage was confirmed with ERCP or percutaneous transhepatic cholangiography and by the demonstration of leakage of contrast medium into the peritoneal cavity. A bile duct stricture was defined as abrupt luminal narrowing with proximal ductal dilatation.

\section{Endoscopic procedure}

Antibiotics were routinely administered before the endoscopic procedure. All patients were sedated with intravenous midazolam and meperidine. ERCP was performed by experienced endoscopists, with a duodenoscope (Olympus Optical, Tokyo, Japan).

The site of the bile leak was assessed on ERCP. In most cases, a sphincterotomy was performed, and then a 5-F nasobiliary catheter (NBC) was inserted. If the bile leak was accompanied by a bile duct stricture, the stricture was dilated with an 8- to 10-mm diameter balloon. Then either a 5-F NBC was inserted across the bile duct stricture or endoscopic retrograde biliary drainage (ERBD) was performed, depending on the aspects of the bile leak and the bile duct stricture. The optimal plastic stent length and diameter were determined by the location of the bile duct strictures. Patients treated with the placement of an NBC underwent NBC cholangiography. When the leak was no longer evident on follow-up NBC cholangiography or ERCP, the treatment was considered completed. ERBD was in place for 3 months. After 3 months, the stent was removed if the bile leak was resolved. If bile leak persisted, the stent was changed.

\section{Analysis of outcome}

Technical success was defined as the resolution of the bile leak on repeat cholangiography. Clinical success was defined as improvement in liver function and clinical manifestations related to the bile leak. Adverse events were defined according to the standard consensus criteria. ${ }^{15}$

All statistical analysis was performed with SPSS version 14.0 (SPSS Inc., Chicago, IL, USA). Categorical variables were compared with a chi-square test or Fisher exact test. A p-value of $<0.05$ was considered statistically significant.

\section{RESULTS}

\section{Baseline characteristics}

The baseline characteristics of the patients are summarized in Table 1. Bile leaks occurred in 42 of 1,430 patients (2.9\%) who underwent liver transplantation. The 42 patients consisted of 32 men and 10 women with a mean age of 46.3 years (range, 19 to 64 years). The underlying diseases were liver cirrhosis in 18 patients (hepatitis B cirrhosis, 14 patients; alcoholic cirrhosis, three patients; autoimmune cirrhosis, one patient), hepatocellular carcinoma in 15 patients, fulminant hepatitis in five patients (hepatitis B, three patients; toxic hepatitis, two patients), Wilson's disease in three patients, and autosomal dominant polycystic kidney disease in one patient.

Bile leaks occurred in 26 of 1,095 patients (2.4\%) who underwent LDLT, five of 140 (3.6\%) who underwent CDLT, and 11 of 195 (5.7\%) who underwent LDLT with dual grafts (Table 2). Bile leaks were observed more in the LDLT with dual graft group than in the CDLT and LDLT groups. Bile leaks alone were observed in 22 of the 42 patients (59.5\%) who had ERCP. Bile leaks with bile duct strictures were seen in 20 of the 42 patients (40.5\%) who had ERCP. The median time from liver transplantation to occurrence of bile leaks was 42 days (range, 3 to 371 days). The 42 patients underwent a total of 59 ERCPs. The mean number of ERCPs was 1.4 (range, 1 to 8).

Of the patients who underwent ERCP, technical success was achieved in 32 (76.2\%), and clinical success was achieved in 27 (64.3\%). There was no significant difference between these two patient groups in terms of donor type (Table 3). In the 40 patients treated with NBC placement, the mean duration of the NBC placement was 13.2 days (range, 2 to 81 days). 


\section{Bile leakage}

The median interval between the liver transplant and the onset of the bile leak was 84 days (range, 11 to 371 days). The mean number of ERCPs was 1.32 (range, 1 to 4). In the 22 patients with bile leaks alone, the bile leak was located at the anastomosis site in 10 (45.5\%), at the external stent tract in six (27.3\%), at the T-tube site in four (18.2\%), and at the cystic duct stump in two (9.1\%) (Table 4).

In the bile leakage group, all patients were treated with NBC

Table 1. Baseline Characteristics of the 42 Patients

\begin{tabular}{|c|c|}
\hline Characteristic & No. of patients \\
\hline Sex, male:female & $32: 10$ \\
\hline Mean age (range), yr & $46.3(19-64)$ \\
\hline \multicolumn{2}{|l|}{ Underlying diseases } \\
\hline $\mathrm{LC}$ & 18 \\
\hline $\mathrm{HCC}$ & 15 \\
\hline Fulminant hepatitis & 5 \\
\hline Other & 4 \\
\hline \multicolumn{2}{|l|}{ Types of donor } \\
\hline LDLT & 26 \\
\hline CDLT & 5 \\
\hline Dual LDLT & 11 \\
\hline \multicolumn{2}{|c|}{ Types of bile duct reconstruction } \\
\hline D-D & 30 \\
\hline D-D with H-J & 11 \\
\hline $\mathrm{H}-\mathrm{J}$ & 1 \\
\hline \multicolumn{2}{|l|}{ Types of injury } \\
\hline Leak & 22 \\
\hline Leak with stricture & 20 \\
\hline \multicolumn{2}{|l|}{ Types of site } \\
\hline Anastomosis & 27 \\
\hline External stent tract & 7 \\
\hline T-tube & 4 \\
\hline Cystic duct & 3 \\
\hline Duct of Luschka & 1 \\
\hline
\end{tabular}

LC, liver cirrhosis; HCC, hepatocellular carcinoma; LDLT, living donor liver transplantation; CDLT, cadaveric donor liver transplantation; D-D, duct-to-duct anastomosis; H-J, hepaticojejunostomy. placement (5-F) with endoscopic sphincterotomy (EST) (Fig. 1). The median duration of the NBC placement was 9 days (range, 2 to 81 days). In the 22 patients with bile leaks alone, endoscopic treatment was technically successful in 19 (86.4\%). Endoscopic management failed in three patients. In these three patients, bile leaks occurred at the anastomosis site. Of the three patients, two required surgery, and one required PTBD. One of the patients who underwent surgery died of sepsis related to the bile leak. Clinical success was achieved in 17 of 22 patients (77.3\%). The complaints of two patients were resolved in follow-up NBC cholangiography, but these patients died of sepsis related to the bile leak. In these two patients, the bile leak occurred at the anastomosis site.

\section{Bile leaks with bile duct strictures}

The median interval between the liver transplant and the onset of a leak with a bile duct stricture was 22 days (range, 3 to 148 days). The mean number of ERCPs was 1.5 (range, 1 to 8). Bile leakage with bile duct stricture was located at the anastomosis site in 17 of 20 patients (85\%). Bile leakage with bile duct

Table 2. Frequency of Occurrence of Bile Leaks according to Donor Type

\begin{tabular}{lc}
\hline \multicolumn{1}{c}{ Types of donor } & Bile leakage $(\mathrm{n}=42)$ \\
\hline CDLT $(\mathrm{n}=140)$ & $5(3.6)^{*}$ \\
LDLT $(\mathrm{n}=1,095)$ & $26(2.4)^{*}$ \\
LDLT with dual grafts $(\mathrm{n}=195)$ & $11(5.7)^{*}$
\end{tabular}

Data are presented as number (\%).

CDLT, cadaveric donor liver transplantation; LDLT, living donor liver transplantation.

${ }^{*} \mathrm{p}=0.039$, comparison of bile leakage between donor types.

Table 3. Outcome of Endoscopic Treatments

\begin{tabular}{lccc}
\hline \multicolumn{1}{c}{ Types of injury } & $\begin{array}{c}\text { No. of } \\
\text { patients }\end{array}$ & Technical success & Clinical success \\
\hline Leak & 22 & $19(86.4)^{*}$ & $17(77.3)^{\dagger}$ \\
Leak with stricture & 20 & $13(65.0)^{*}$ & $10(50.0)^{\dagger}$ \\
Total & 42 & $32(76.2)$ & $27(64.3)$ \\
\hline
\end{tabular}

Data are presented as number (\%).

${ }^{*} \mathrm{p}=0.152$, comparison of the technical success rate between injury types; ${ }^{\dagger} \mathrm{p}=0.107$, comparison of the clinical success rate between injury types.

Table 4. Outcome of Endoscopic Treatments in 22 Patients with Bile Leaks Only

\begin{tabular}{llcccc}
\hline \multicolumn{1}{c}{ Types of site } & Types of surgery (no.) & No. of patients & Treatment & Technical success, no. (\%) & Clinical success, no. (\%) \\
\hline Anastomosis & LDLT (6), dual LDLT (4) & 10 & EST and ENBD & $7(70.0)$ & $5(50.0)$ \\
External stent tract & LDLT (6) & 6 & EST and ENBD & $6(100.0)$ & $6(100.0)$ \\
T-tube & CDLT (4) & 4 & EST and ENBD & $4(100.0)$ & $4(100.0)$ \\
Cystic duct & LDLT (1), dual LDLT (1) & 2 & EST and ENBD & $2(100.0)$ & $2(100.0)$ \\
\hline
\end{tabular}

LDLT, living donor liver transplantation; EST, endoscopic sphincterotomy; ENBD, endoscopic nasobiliary drainage; CDLT, cadaveric donor liver transplantation. 

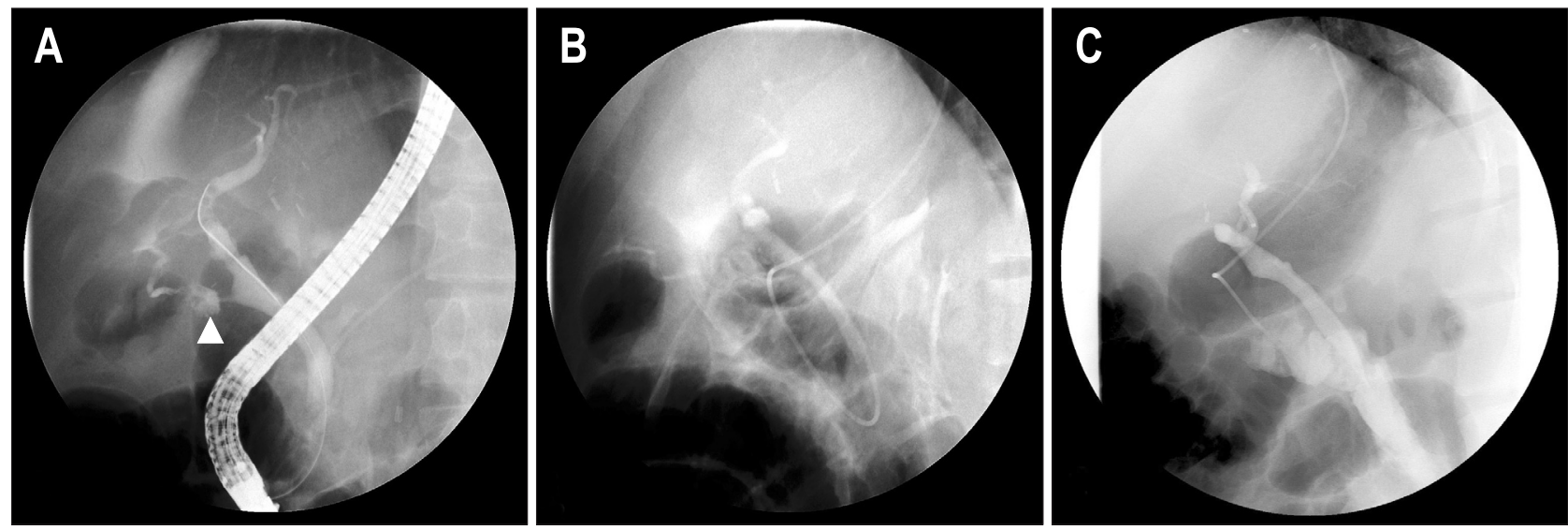

Fig. 1. (A) Retrograde cholangiogram showing leakage at the external stent site (arrowhead). (B) Cholangiogram showing the placement of a 5-F nasobiliary catheter across the leak. (C) Occlusion cholangiogram 11 days later showing that the leak had closed.

Table 5. Outcome of Endoscopic Treatments in 20 Patients with Bile Leaks with Strictures

\begin{tabular}{llclcc}
\hline \multicolumn{1}{c}{ Types of site } & \multicolumn{1}{c}{ Types of surgery (no.) } & No. of patients & \multicolumn{1}{c}{ Treatment (no.) } & Technical success, no. (\%) & Clinical success, no. (\%) \\
\hline Anastomosis & LDLT (10), dual LDLT (7) & 17 & EST and ENBD (16), EST (1) & $10(58.8)$ & $7(41.2)$ \\
External stent tract & LDLT (1) & 1 & EST and ENBD & $1(100.0)$ & $1(100.0)$ \\
Cystic duct & LDLT (1) & 1 & ERBD & $1(100.0)$ & $1(100.0)$ \\
Duct of Luschka & CDLT (1) & 1 & EST and ENBD & $1(100.0)$ & $1(100.0)$ \\
\hline
\end{tabular}

LDLT, living donor liver transplantation; EST, endoscopic sphincterotomy; ENBD, endoscopic nasobiliary drainage; ERBD, endoscopic retrograde biliary drainage; CDLT, cadaveric donor liver transplantation.

stricture occurred at the external stent tract, at the cystic duct stump, and at the duct of Luschka in three patients (Table 5).

Endoscopic treatment for bile leaks with strictures included NBC placement with EST ( $n=18)$, EST alone $(n=1)$, and ERBD alone $(n=1)$. In the 18 patients treated with NBC placement, the median duration of the NBC placement was 8 days (range, 2 to 42 days). In the patients treated with EST with NBC placement, three patients did not respond to the initial treatment. In two of these patients, the bile leaks were resolved, but a persistent bile duct stricture was confirmed at follow-up, and balloon dilatation with an 8-mm diameter balloon and ERBD was performed. ERCP performed 3 months later demonstrated resolution of the stricture (Fig. 2). In the remaining patient, a persistent bile leak was confirmed at follow-up, and balloon dilatation with an 8-mm diameter balloon and ERBD was performed. Cholangiography performed 15 days later demonstrated resolution of the bile leak, but a persistent stricture was confirmed, and PTBD was conducted.

In the 20 patients with bile leaks with bile duct strictures, endoscopic treatment was technically successful in 13 patients (65.0\%). EST alone was chosen for one patient. In the patient treated with EST alone, ERCP failed to clearly identify the source of the leak. The source was not found with laparotomy. PTBD was performed, and the bile leak site was located at the anastomosis site. ERBD alone was performed in one patient. Endoscopic management failed in seven patients. In all seven patients, bile leaks with strictures occurred at the anastomosis site. Of the seven patients, one required PTBD following surgery, and six required PTBD. Clinical success was achieved in 10 of 20 patients (50\%). In the remaining 10 patients with clinical failure, the complaints of three patients were resolved in followup NBC cholangiography. However, one of these three patients underwent retransplantation because of graft failure. In the remaining two patients, PTBD was performed due to persistent abdominal pain related to bile duct strictures. One patient died of fungal pneumonia unrelated to the bile leak.

\section{Adverse events of ERCP}

The ERCP-related complication rate was 9.5\% (4/42). One patient developed a perforation after EST and an NBC placement for a bile leak. This patient underwent surgical repair, and the leak was stopped. Three patients developed bleeding. One of these patients developed bleeding after ERBD for a bile leak with strictures and was successfully managed with embolization. In the other two patients, bleeding developed after EST and an NBC placement for a bile leak with strictures and was successfully managed with ERCP.

\section{Follow-up}

During the median follow-up period of 42.5 months (range, 1.0 to 67 months), eight of the 42 patients (19\%) who were treated for bile leaks experienced bile duct strictures. Seven of the eight 

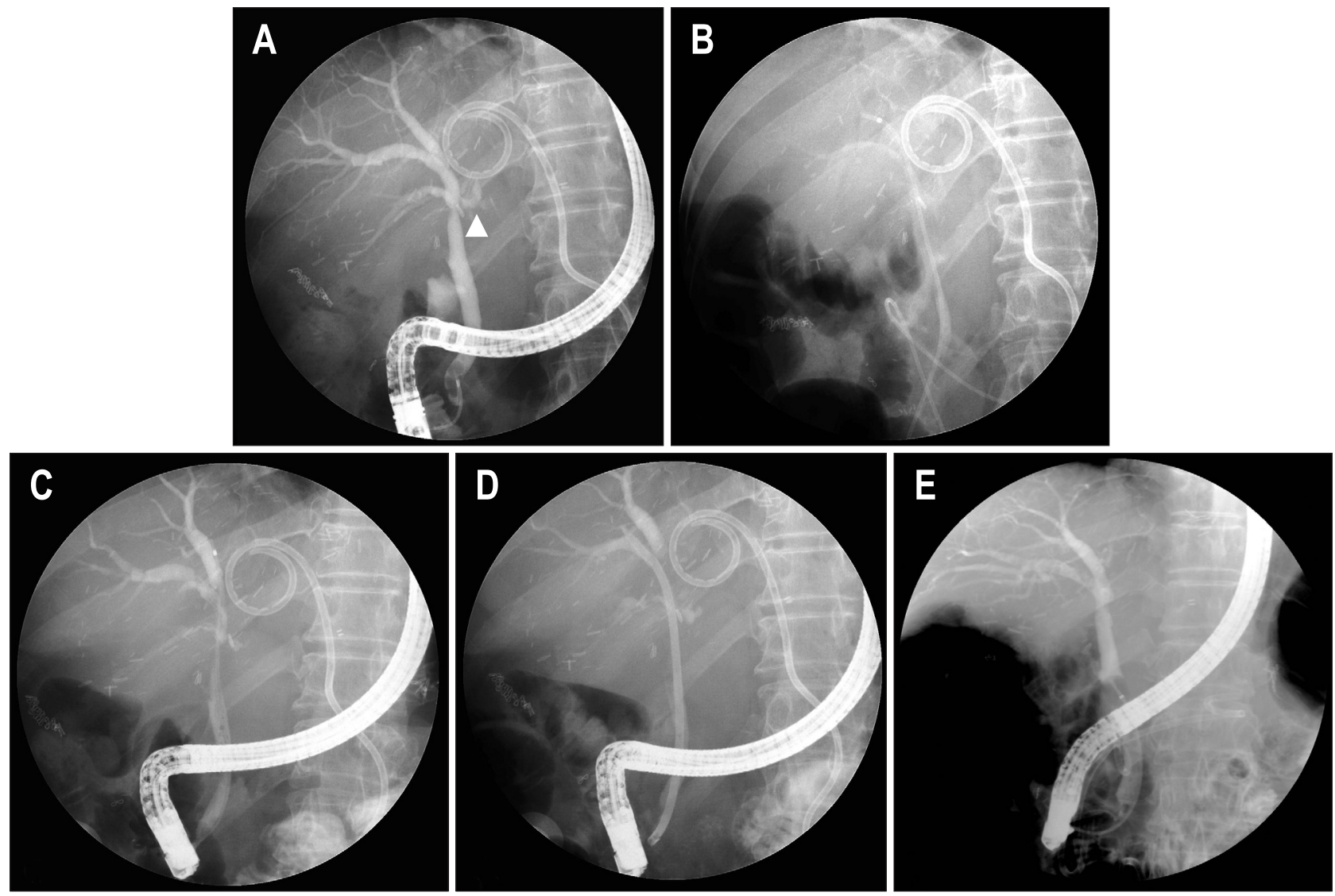

Fig. 2. (A) Retrograde cholangiogram showing an anastomotic leak (arrowhead). (B) Cholangiogram showing placement of a 5-F nasobiliary catheter across the leak. (C) Cholangiogram 5 days later demonstrating closure of the leak and an anastomotic stricture. (D) Stricture treated with balloon and stent insertion. (E) Cholangiogram showing resolution of the anastomotic stricture after a stent was inserted.

patients who developed bile duct strictures were in the bile leakage with duct strictures group. The bile leaks were resolved with placement of an NBC. However, the bile duct strictures were persistent. The patients required additional treatment such as ERBD and PTBD. Four of those patients were treated with PTBD. The others were treated with ERBD. One patient was in the bile leakage alone group. This patient was treated with ERBD. All patients recovered well with ERBD or PTBD.

\section{DISCUSSION}

Bile leak is the most common short-term adverse event and cause of mortality following liver transplantation. ${ }^{9,16,17}$ For example, $19 \%$ of patients with bile leaks died during the perioperative period due to bile leak-related adverse events, and the 1- and 2-year survival rates for patients with bile leaks are 76\% and 65\%, respectively, versus $89 \%$ and $85 \%$ for those without bile leaks. ${ }^{18}$

Our study shows the results of a large cohort of patients who developed bile leaks after liver transplantation (CDLT, LDLT, or LDLT with dual grafts) and were treated with ERCP. The main causes of biliary drainage or T-tube leakage include biliary drainage or the dislocation of T-tubes that are scheduled for removal several months after surgery. ${ }^{7,9,12,19,20}$ Anastomotic leaks may be caused by stomal ischemia, which is related to injury of the donor bile duct, a prolonged preservation time, or post-liver transplantation thrombosis of the hepatic artery. ${ }^{7,21}$ Anastomotic leaks are not as uncommon as T-tube exit leaks, ${ }^{7}$ and anastomotic leaks are more likely than T-tube leaks to occur early. ${ }^{7,9}$ Patients with anastomotic leaks have more adverse events, such as graft dysfunction, infection, peritonitis, abdominal abscess, or sepsis. The long-term prognosis is relatively worse. ${ }^{7,9}$ Less frequent causes include leaks from the cut surface of a liver graft that has been surgically reduced or obtained in a split-liver or living-donor procedure, ${ }^{10}$ leaks from unobserved accessory ducts in the gallbladder fossa, ${ }^{22}$ and leaks at incompletely closed cystic duct remnants. ${ }^{23}$

In our study, bile leaks occurred more frequently in the LDLT with dual graft group than in the CDLT and LDLT groups. Possible explanations include the greater technical demands of LDLT with dual grafts and the inferior quality of the LDLT graft or the caliber of LDLT donor vessels available for anastomosis. ${ }^{24}$ In the LDLT with dual grafts procedure performed at our center, the bile ducts are reconstructed with duct-to-duct anastomosis and hepaticojejunostomy. ${ }^{2}$ These complicated procedures may contribute to the increased rate of bile leaks. Of the patients 
who had bile leaks after liver transplantation, four died: three of sepsis related to the bile leaks and one of fungal pneumonia. In four patients, bile leaks developed due to anastomotic leaks. Two patients who underwent LDLT developed graft dysfunction, and retransplantation was performed. This may suggest that anastomotic leaks are related to more adverse events and a worse prognosis.

The principal aim of nonoperative management is diversion of bile away from the leak site by decompressing the biliary tree. Many approaches are available to treat bile leaks after liver transplantation. Surgery has been advocated for managing complete disruption of duct-to-duct anastomosis and cystic duct leaks. ${ }^{25}$ However, reoperation in patients who have undergone liver transplantation confers greater morbidity and mortality than nonoperative approaches. ${ }^{25}$ Percutaneous placement of a transhepatic drainage catheter often closes the leak. However, this approach may be particularly difficult technically because the biliary tree often is not dilated in the setting of a biliary fistula. In addition, the potential risk of injury to the donor liver may restrict the use of a percutaneous drain. ${ }^{26}$

Most investigators consider endoscopic therapy to be the management of choice for adults and children after liver transplantation, regardless of the presence or absence of an anastomotic leak, a T-tube leak, and even partial disjunction of the stoma. ${ }^{9}$ In our study, the bile leaks were initially treated with standard ERCP, by using conventional procedures: EST alone, EST with NBC placement, and ERBD placement. EST as the only treatment for bile leaks may be complicated by bleeding or perforation. ${ }^{27}$ Although Wolfsen et al. ${ }^{28}$ found that EST alone healed 78\% of bile leak cases, the efficiency of EST remains uncertain. Most endoscopists disagree that EST alone is effective for bile leaks. In our study, EST alone was performed in one case, but this approach failed. It has been stated that a wellplaced NBC may cure all bile leakage. ${ }^{29}$ Stent placement is an effective therapy in bile leakage. Morelli et al. ${ }^{7}$ reported that the first stent placement healed $88 \%$ of bile leak cases. In the present series, one patient in the bile leakage with stricture group was treated with ERBD, and this method was successful. An NBC can provide negative pressure suction of bile, and effective drainage can be conveniently observed and recorded. Cholangiography through the NBC can assess the healing of the leak and possible bile duct-related adverse events without the need for repeated ERCP. The bile leaks were managed with EST with NBC placement in the majority of cases (40/42, 95.2\%). Of the patients treated with EST with NBC placement, 32 were successfully managed with EST with endoscopic nasobiliary drainage. However, the main disadvantage of NBC placement is the need for skillful and careful nursing, especially for post-liver transplantation patients with hepatic encephalopathy, who may rip out the NBC and cause disjunction of the stoma.

In 20 of 42 patients (47.6\%), the bile leaks were associated with bile duct strictures. Bile leaks are an independent risk fac- tor for the development of anastomotic strictures. ${ }^{30}$ Although we do not know exactly the cause of the association, it may be due to peribiliary fibrosis, which can be induced by local inflammation resulting from bile leaks. ${ }^{31}$ The technical and clinical success rates for patients with bile leaks alone were $86.4 \%$ and $77.3 \%$, respectively, versus $65.0 \%$ and $50.0 \%$ for those with bile leaks combined with bile duct strictures. Treatment failure occurred via anastomotic leaks in both groups. Nonetheless, the technical and clinical success rates were lower in the bile leaks with bile duct strictures group. When only bile leaks in the bile leakage with bile duct stricture group are considered, endoscopic management was successful. However, clinically, especially for anastomotic bile leaks with strictures, the results were unsatisfactory. Rossi et al. ${ }^{32}$ reported that 10 of 12 patients with anastomotic strictures had a patent anastomosis for more than 1 year after the endoscopic stent was removed. Endoscopic management should include biliary stent placement after stricture dilatation and has been highly successful. ${ }^{6}$ Schwartz et al. ${ }^{33}$ reported a low success rate for the treatment of anastomotic strictures with dilation without stent placement. In this series, bile duct dilation without stent placement was performed. For patients with bile leaks with bile duct strictures, stricture dilation followed by the placement of a stent is recommended.

Although endoscopic sphincterotomy, NBC placement, and/ or stent insertion is commonly used to treat bile leaks after liver transplantation, there is no consensus about which of these maneuvers provides the best outcome. ERCP is a well-known treatment for bile leaks after cholecystectomy and liver resection. The type of bile leak such as a leak after accidental dislodgement of an indwelling tube is different from a bile leak after liver transplantation. For this type of leak, endoscopic treatment is effective. ERCP is also effective for bile leaks after surgery such as cholecystectomy. However, our data suggest that ERCP is an effective and safe therapeutic modality for bile leaks after liver transplantation, thus obviating the need for surgical revision or placement of percutaneous drains, which are often long-term and less favored by patients. Especially, ERCP is an effective treatment for patients who develop bile leaks only. We propose that ERCP should be considered an initial, less invasive therapeutic modality in post-liver transplantation patients. Nonetheless, further studies are needed to determine the most cost-effective endoscopic method for treating liver transplantation patients.

\section{CONFLICTS OF INTEREST}

No potential conflict of interest relevant to this article was reported.

\section{REFERENCES}

1. de Villa VH, Lo CM, Chen CL. Ethics and rationale of living-donor liver transplantation in Asia. Transplantation 2003;75(3 Suppl):S2-S5. 
2. Lee SG, Hwang S, Park KM, et al. Seventeen adult-to-adult living donor liver transplantations using dual grafts. Transplant Proc 2001;33:3461-3463.

3. Soejima Y, Taketomi A, Ikegami T, et al. Living donor liver transplantation using dual grafts from two donors: a feasible option to overcome small-for-size graft problems? Am J Transplant 2008;8: 887-892.

4. Tarantino I, Barresi L, Petridis I, Volpes R, Traina M, Gridelli B. Endoscopic treatment of biliary complications after liver transplantation. World J Gastroenterol 2008;14:4185-4189.

5. Kim JH, Ko GY, Sung KB, et al. Bile leak following living donor liver transplantation: clinical efficacy of percutaneous transhepatic treatment. Liver Transpl 2008;14:1142-1149.

6. Rerknimitr R, Sherman S, Fogel EL, et al. Biliary tract complications after orthotopic liver transplantation with choledochocholedochostomy anastomosis: endoscopic findings and results of therapy. Gastrointest Endosc 2002;55:224-231.

7. Morelli J, Mulcahy HE, Willner IR, et al. Endoscopic treatment of post-liver transplantation biliary leaks with stent placement across the leak site. Gastrointest Endosc 2001;54:471-475.

8. Polese L, Cillo U, Brolese A, et al. Endoscopic treatment of bile duct complications after orthotopic liver transplantation. Transplant Proc 2007;39:1942-1944.

9. Liao JZ, Zhao Q, Qin H, et al. Endoscopic diagnosis and treatment of biliary leak in patients following liver transplantation: a prospective clinical study. Hepatobiliary Pancreat Dis Int 2007;6:29-33.

10. Johnston TD, Reddy KS, Khan TT, Ranjan D. ERCP in the management of early versus late biliary leaks after liver transplantation. Int Surg 2006;91:301-305.

11. Johnston TD, Gates R, Reddy KS, Nickl NJ, Ranjan D. Nonoperative management of bile leaks following liver transplantation. Clin Transplant 2000;14(4 Pt 2):365-369.

12. Park JS, Kim MH, Lee SK, et al. Efficacy of endoscopic and percutaneous treatments for biliary complications after cadaveric and living donor liver transplantation. Gastrointest Endosc 2003;57:78-85.

13. Chahal P, Baron TH, Poterucha JJ, Rosen CB. Endoscopic retrograde cholangiography in post-orthotopic liver transplant population with Roux-en-Y biliary reconstruction. Liver Transpl 2007;13:1168-1173.

14. Tsujino T, Isayama $\mathrm{H}$, Sugawara $\mathrm{Y}$, et al. Endoscopic management of biliary complications after adult living donor liver transplantation. Am J Gastroenterol 2006;101:2230-2236.

15. Cotton PB, Lehman G, Vennes J, et al. Endoscopic sphincterotomy complications and their management: an attempt at consensus. Gastrointest Endosc 1991;37:383-393.

16. Patkowski W, Nyckowski P, Zieniewicz K, et al. Biliary tract complications following liver transplantation. Transplant Proc 2003;35:2316-2317.

17. Shah SR, Dooley J, Agarwal R, et al. Routine endoscopic retrograde cholangiography in the detection of early biliary complications after liver transplantation. Liver Transpl 2002;8:491-494.

18. Gondolesi GE, Varotti G, Florman SS, et al. Biliary complications in 96 consecutive right lobe living donor transplant recipients. Transplantation 2004;77:1842-1848.

19. Dulundu E, Sugawara Y, Sano K, et al. Duct-to-duct biliary reconstruction in adult living-donor liver transplantation. Transplantation 2004;78:574-579.

20. Liu CL, Lo CM, Fan ST. What is the best technique for right hemiliver living donor liver transplantation? With or without the middle hepatic vein? Duct-to-duct biliary anastomosis or Rouxen-Y hepaticojejunostomy? J Hepatol 2005;43:17-22.

21. Zheng SS, Xu X, Liang TB, Chen HY, Wang WL, Wu J. Biliary complications following early hepatic arterial insufficiency in liver transplantation. Zhonghua Yi Xue Za Zhi 2005;85:1665-1669.

22. Albishri SH, Issa S, Kneteman NM, Shapiro AM. Bile leak from duct of Luschka after liver transplantation. Transplantation 2001;72:338-340.

23. Von Moll LK, Juni JE, Merion RM. Scintigraphic demonstration of accessory hepatic duct leak following liver transplantation. J Nucl Med 1988;29:259-262.

24. Freise CE, Gillespie BW, Koffron AJ, et al. Recipient morbidity after living and deceased donor liver transplantation: findings from the A2ALL Retrospective Cohort Study. Am J Transplant 2008;8:2569-2579.

25. Osorio RW, Freise CE, Stock PG, et al. Nonoperative management of biliary leaks after orthotopic liver transplantation. Transplantation 1993;55:1074-1077.

26. Sherman S, Shaked A, Cryer HM, Goldstein LI, Busuttil RW. Endoscopic management of biliary fistulas complicating liver transplantation and other hepatobiliary operations. Ann Surg 1993; 218:167-175.

27. Sherman S, Jamidar P, Shaked A, Kendall BJ, Goldstein LI, Busuttil RW. Biliary tract complications after orthotopic liver transplantation: endoscopic approach to diagnosis and therapy. Transplantation 1995;60:467-470.

28. Wolfsen HC, Porayko MK, Hughes RH, Gostout CJ, Krom RA, Wiesner RH. Role of endoscopic retrograde cholangiopancreatography after orthotopic liver transplantation. Am J Gastroenterol 1992;87:955-960.

29. Bhattacharjya S, Puleston J, Davidson BR, Dooley JS. Outcome of early endoscopic biliary drainage in the management of bile leaks after hepatic resection. Gastrointest Endosc 2003;57:526-530.

30. Welling TH, Heidt DG, Englesbe MJ, et al. Biliary complications following liver transplantation in the model for end-stage liver disease era: effect of donor, recipient, and technical factors. Liver Transpl 2008;14:73-80.

31. Verdonk RC, Buis CI, Porte RJ, et al. Anastomotic biliary strictures after liver transplantation: causes and consequences. Liver Transpl 2006;12:726-735.

32. Rossi AF, Grosso C, Zanasi G, et al. Long-term efficacy of endoscopic stenting in patients with stricture of the biliary anastomosis after orthotopic liver transplantation. Endoscopy 1998;30:360-366.

33. Schwartz DA, Petersen BT, Poterucha JJ, Gostout CJ. Endoscopic therapy of anastomotic bile duct strictures occurring after liver transplantation. Gastrointest Endosc 2000;51:169-174. 